\title{
Innovating urban public transport: some recent developments in the Netherlands
}

\author{
Rob van der Heijden ${ }^{1,2}$, Raffael Argiolu ${ }^{1}$, Ilona Bos $^{1} \&$ Vincent \\ Marchau $^{2}$ \\ ${ }^{l}$ Nijmegen School of Management, Radboud University, Nijmegen, The \\ Netherlands. \\ ${ }^{2}$ Faculty of Technology, Policy and Management, Delft University of \\ Technology, Delft, The Netherlands.
}

\begin{abstract}
Authorities of urban areas are faced with growing traffic and environmental problems due to an ever-increasing use of cars within the urban area. The challenge is to limit and guide car use. The search for innovative strategies to cope with this challenge in the Netherlands focuses on the integration of three policy ingredients. These are: (a) influencing travel behaviour by offering seamless multi-mobility services, (b) the application of advanced informationand telecommunication technology and (c) the spatial concentration of new economic and residential developments along high quality public transport axes. This chapter discusses these ingredients separately and describes a project in the Dutch city of Eindhoven where these ingredients come together. The project, called 'Phileas' is a public transport service based on a fully new developed semi-automated bus on a network of dedicated lanes, offering a high level of information to the travellers and connecting new spatial developments by this public transport network.
\end{abstract}

\section{Introduction}

Urban areas in the developed countries all over the world increasingly suffer from the growth in car ownership and the intensive use of cars in these areas [1]. This trend demands an increasing amount of space, both in the case of car use (growing road capacity) as in the case of non-use (parking space). Moreover, cars produce noise, they are generally heavily involved in too many and often 
severe traffic accidents and their emissions contribute significantly to deterioration of the urban living climate. For instance, recent studies in the Netherlands indicated that about 5000 individuals die every year due to environmental pollution by motorised traffic. Moreover, the annual number of fatalities and injured people in urban areas due to traffic accidents is significant in the Netherlands.

Of course, we know that the policy answers to these developments are not easy to find. A careful balance has to be found with the positive aspects of car use, such as individual accessibility to a wider range of destinations or the possibility to live at a greater distance from work or school but probably in a place that fits better to individual living preferences. Therefore, just forbidding the use of the car on a large scale in urban areas is not a solution, although for some parts of the city (e.g. shopping areas) free access by car is unthinkable nowadays. Other measures generally focus on a more subtle impact. One example concerns parking regulation in terms of limiting the amount of parking lots, increasing the price of parking or implementing a parking guidance system. Another example is traffic flow regulation by speed control and guided routing to improve throughput in the network and limit traffic flow in congestionsensible areas. Moreover, we mention the policy measures aimed at using alternative transport modes, for example by creating a special urban bicycle network or offering a variety of public transport services.

The success of transport and road traffic management in urban areas depends upon the integration of these different measures. They have to work together in a synergetic way to cause a significant impact on urban car use. Practice shows us that a switch to alternative transport modes is not easily made and the acceptance of a high price for urban accessibility by car is on average not very high. Therefore, large cities in developed countries facing very severe problems that can no longer be solved by subtle measures are increasingly intended to implement more drastic policies. These are based on measures strongly limiting the use of the car, knowing that congestion is becoming so severe in these cities that car drivers are ready to accept them. We refer to, for example, the road pricing policy in Rome and London. The volume of traffic in cities of this size is, however, that big that an extended network of high-quality public transport services can be offered as an alternative. The high volume of intra-urban daily trips legitimates, for instance, large investments in a dedicated network (often underground) for high frequency public transport services. Many world cities have such networks, daily accommodating millions of passengers.

Most cities, however, do not have the size of London or Paris or Rome. Although smaller in size, many of them nevertheless do struggle with severe traffic problems. And city authorities in these cities are also trying to find ways to handle the ever-growing amount of cars moving around. In the Netherlands, two of the largest cities (Amsterdam and Rotterdam) have invested in the past and are still investing in an underground rail system combined with a severe parking price policy for inner urban areas. This policy is not without debate. A recent decision to construct a new line as part of the underground rail system in Amsterdam triggered an intensive public debate because of the fear of too high costs, too low societal benefits and safety concerns. Other (on average much 
smaller) cities in the Netherlands try to seek a balance between measures for parking, traffic management on the urban road network and a (partly dedicated) network of buses, trams and light rail at surface level. The success of this approach is not spectacular, given the ever-growing congestion problems in morning and evening peak hours in and around Dutch urban agglomerations.

Therefore, local and regional policy makers are permanently searching for innovative solutions and policy strategies. Recent discussions in the Netherlands put an emphasis on changing travel behaviour by the integration of the following three ingredients. First, more attention should be paid to measures that contribute to what is called 'chain mobility' or 'seamless multi-modal mobility': the easy switch between different transport modes, in particular, resulting in an easy use of bicycle or public transport services in urban areas (see e.g. [2, 3]). This requires among others a system of $P \& R$ facilities, high quality urban public transport services (free lanes, high frequency) and restrictive inner-city parking policies. A second ingredient concerns a much more intensive use of advanced information and telecommunication technology (ICT) in transport and traffic management. This is expected to significantly influence the performance of transport services. A third ingredient is the spatial concentration of new economic and residential activities in nodes of public transport services. The assumption is that this will stimulate the use of public transport.

To find a good balance between these three approaches and to integrate them into real-world innovations is a real challenge. In this chapter we will go into more detail with respect to this line of innovation for urban transport, focusing on the situation in the Netherlands. That is, we will present some empirical results of recent research and discuss some recent practices. The structure of this chapter is as follows. First, in section 2 we will present a conceptual model of how we view the transport system. This is important for understanding the various discussions. Moreover, it makes clear that steering the processes within this system towards the intended development is not an easy task. In section 3 we will go into more detail with respect to the first ingredient of innovative urban mobility policy in the Netherlands: the focus on the concept of seamless multi-mobility. In this context a link is made to recent research on behavioural choices of travellers. Next in section 4 some relevant ICT developments are briefly addressed. We will indicate how these can be used to innovate urban transport. In section 5 the third ingredient is discussed: the spatial location development policy. In section 6 these developments come together in the description of an innovation in public transport realised in the city of Eindhoven in the Netherlands. The system that has been taken into operation in the summer of 2004 is called 'Phileas'. Finally, section 7 finishes this chapter with some conclusions and discussion.

\section{A view on the transport system}

To understand innovation in (urban) transport, it is important to apply a descriptive, explaining framework. In the recent past, we presented $[4,5]$ the conceptual framework for the transport system as presented in fig. 1. It focuses 
on the functional characteristics of different subsystems of the transport system. Figure 1 splits the transport system into seven subsystems: four physical subsystems (infrastructure, vehicles, cargo \& passengers and spatial/economic patterns) and three 'market' subsystems (the traffic market, the transport service market and the mobility market). These seven subsystems roughly tell us how major processes in the transport system function. Each subsystem generates its own unique processes and problems and has unique stakeholder interactions. From an analytical point of view, it is valid to regard them as subsystems. From a synthesis point of view (e.g. in policymaking), it is important to pay sufficient attention to the interactions between the subsystems. A lower subsystem facilitates (supports) the processes within the higher subsystems. A higher subsystem places functional requirements on services that are offered by the lower subsystem. For example: there will be no traffic without roads (traffic requires roads), but once there are roads they support a large variety of traffic processes. Hence, in order to understand the conceptual scheme, we will briefly discuss each subsystem in more detail.

The subsystem 'Physical infrastructure' refers to the variety of infrastructure networks and facilities for different travel modes (road, rail, shipping, pipelines, air). These infrastructures are a necessary condition to facilitate traffic flows. Typical processes are the planning, design, realisation and maintenance of infrastructure. Increasingly, there appears to be a shortage of road infrastructure capacity to handle total traffic demand. This shortage is subject to intervention in the so-called 'Traffic market'. Operational traffic management aims at handling this shortage. The character and intensity of interventions can change due to, for example, the construction of more infrastructure capacity and/or the use of ITS applications to improve infrastructure capacity use.

The subsystem 'Vehicles' refers to the fleet of vehicles that is available to transport passengers or freight from one place to another. The use of vehicles asks for traffic rules and infrastructure capacity. The nature of this demand varies with the different functional characteristics of each transport fleet (e.g. maximum speed, professional drivers or not, use at dedicated lanes or in mixed traffic). Most of these fleets are subject to continuous technical improvements, among which the introduction of electronic devices to support driver tasks. Choices regarding the use of subsets of the available vehicle capacity to transport passengers or freight result from decision making by stakeholders operating in the subsystem called the 'Transport service market'. In this market, logistics providers, transport companies and the passengers themselves seek a match between the demand for trips and the transport options. This matching process is sensitive to aspects such as costs and time. Moreover, the access to information and the reliability of information concerning the alternative options increasingly appears to substantially influence logistic decisions.

The development of transport services is a reaction to an overt volume of to be transported 'Freight and passengers'. This is measurable in terms of the number of passengers and the freight volume to be transported at a certain place and time. This demand basically results from the 'Spatial and economic patterns' related to production and consumption activities in society, the top-level subsystem of the conceptual scheme. At that subsystem decisions are taken on, 
for instance, the nature and spatial pattern of economic activities, the amount of free time for inhabitants and on policies for urban spatial development. The resulting societal structure generates a certain hidden demand for transport. The hidden demand and overt demand are not equal. The degree, to which this hidden demand results in overt transport behaviour, therefore depends upon the operating of an intermediate market, here labelled the 'Mobility market'. The transfer from hidden to overt transport needs, heavily depends upon the trade-off made by individuals between the utility of a spatial movement and the level of resistance (time, money, effort). This is influenced by aspects such as the size of available time and financial budget, transport pricing policies and the possibilities to substitute physical trips by virtual trips (e.g. using internet).

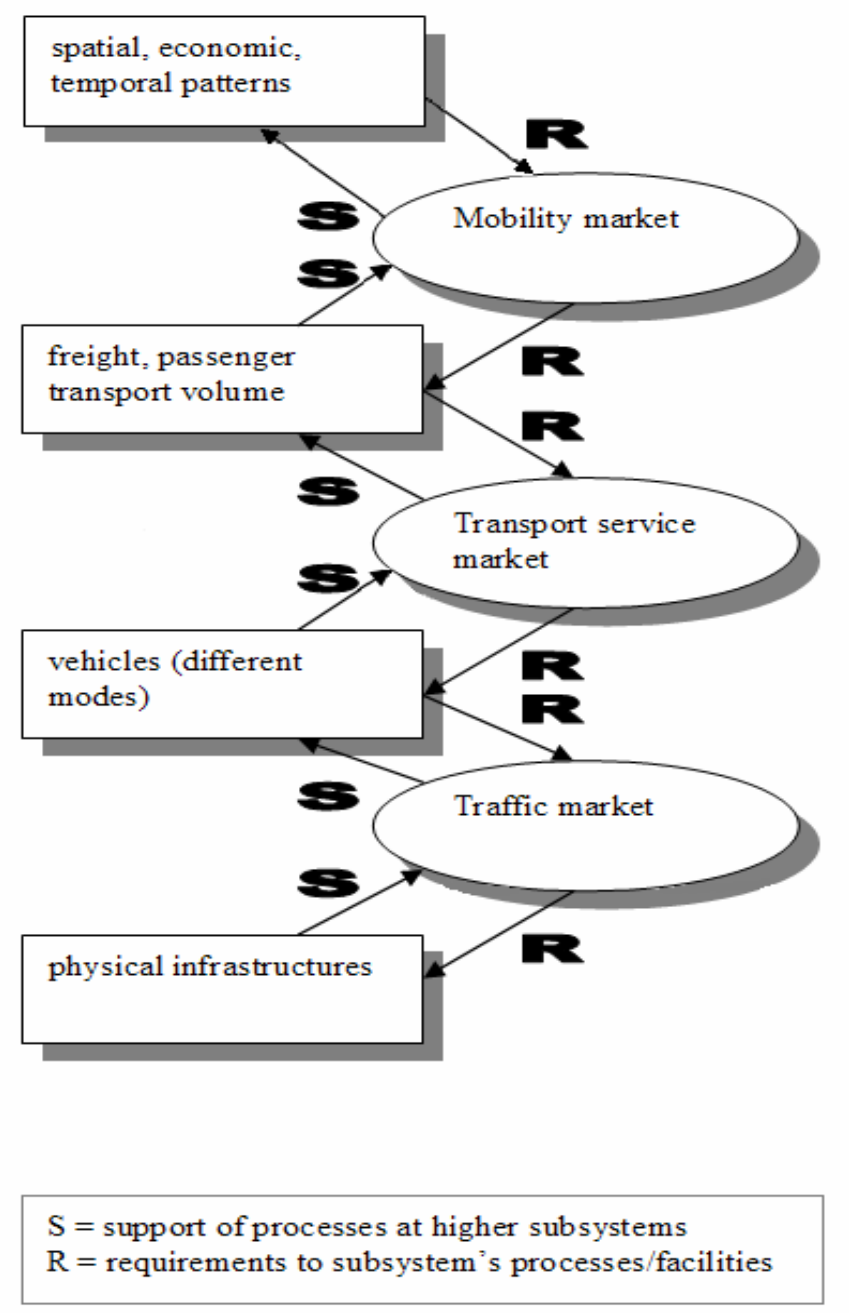

Figure 1: A transport systems view. 
This conceptual model teaches us that different subsystems are functionally linked to each other and, hence, should be approached in an integrative way in the context of finding innovative strategies. It indicates that measures taken to influence processes at each of the three markets (either by changing the supply side or the demand side of that market) should take into account the fact that there might exist crucial conditions for success resulting from the operation of the other markets. Moreover, impacts of the measures will not be limited to the specific market that is subject to influence, but other markets might also experience certain effects. From this perspective, we recall the three ingredients for urban transport policy innovation to position them in the context of the transport system view:

(a) advanced ICT influences processes at the mobility market (substitution of transport need), the transport service market (transport service quality) and the traffic market (vehicle driving and road infrastructure use);

(b) traveller's choice behaviour is directly linked to processes at the transport service market aimed at offering seamless multi-mobility transport services:

(c) spatial planning and location development is primarily linked to processes at the mobility market.

Hence, we face a complex mix of decisions and contexts. An evident approach is not available, but plausible and promising combinations of approaches of the three markets might be found.

Now we have improved our understanding of the complexity of the transport system, we can focus more specifically on the ingredients for innovations that have a high priority in the Dutch transport policy.

\section{Seamless multi-modal mobility}

In this section we will begin by briefly describing the concept of multi-modal mobility. Then some results of a recent study on behavioural aspects of this type of travelling will be presented. We will end up with some conclusions.

\subsection{The Concept}

Policy making in transport management has for a long time been characterised by a separated attention for different transport modes: the car, the bus, the bicycle or the train. This is due to the fact that the emphasis in policy has long been laid on supply of infrastructure (networks for the car, train and bicycles) and related services (road traffic management, parking, routing of public transport). Hence, authorities typically focused on the traffic market. This even resulted in traffic specialists for each of the modes.

However, the increasing amount of research on the behavioural aspects of travelling has shown us that this supply-based approach does not fit very well with the complex time-space behaviour of individuals. This research has helped us to gradually improve our understanding of door-to-door travel behaviour of people. In that context, we know that a substantial share of trips is not based on 
the use of just one single transport mode, but on the combination of several transport modes. For example, many commuters in the Netherlands go to the train station by car, bicycle or bus and then use the train to travel to their destination. We also know from analyses of decision making by travellers that they make a trade-off between a variety of conditions, such as the possibility to park the car or the bicycle close to the public transport stop, the time loss for switching mode, the social safety, the costs, et cetera. Analyses of overt travel behaviour teach us that the simple mono-modal supply policy is less effective than intended.

In terms of policy making, these gained insights in travel behaviour and, in particular, the need for combining services of different transport modes and creating a variety of good conditions for that integration process, have resulted in the concept of 'chain mobility' or 'seamless multi-modal travelling'. This concept has been promoted since the mid 1990s [2] and has, among others, resulted in new scientific research programs. Seamless multi-modal travelling is considered an attractive alternative for door-to-door car-based trips towards inner-urban destinations. Moreover, it is a means to create more volume for public transport services and consequently might contribute to the further improvement of public transport services. Since the past decade this policy among others has resulted in various initiatives for the planning and construction of P\&R facilities at the edge of urban areas, various initiatives to improve bicycle parking facilities at train stations, attempts to co-ordinate train and bus service scheduling and ticketing, systems for improving pre-trip travel information, and so on. In sum, transport planners and policy makers are switching to strategies that link traffic market measures to innovations at the transport service market. And the first ideas are explored to also make a structured link to decisions taken at the level of the mobility market. Basically, this link regards decisions on spatial planning at urban network level: where should new residential and business area developments be developed, how should the road network be changed?

A crucial assumption underlying these developments is that travellers choose their travel mode on a trade-off between a variety of decision criteria varying from the classical ones such as travel time and costs to issues of comfort, reliability or social safety. Moreover, it is assumed that people are sensitive to changes in these criteria for their final travel choices. These assumptions have been researched by Bos in recent years. Parts have been published $[6,7,8]$. In the next subsection we will describe some of the results, since behaviour of travellers is one of the critical factors for success of innovative policy strategies based on seamless multi-modal mobility services.

\subsection{Some findings on traveller's behaviour}

The study focused on car driver's choices with regard to P\&R facilities, a major issue in the context of seamless multi-modal travelling. Such facilities are under development at edges of many urban areas to collect car drivers and transport them by public transport inbound the city. Part of the study focused on the identification of the set of attributes of the P\&R travel concept that are important 
to driver's travel decisions. Moreover, special focus was paid to the grouping of these attributes into basic traveller's decision constructs. The attributes were specified based on an extended literature review. An empirical study was performed that aimed to identify (a) the higher order constructs used by travellers when choosing or evaluating P\&R facilities and (b) the relationships between attributes and higher order decision constructs.

To derive the decision constructs based on an empirical basis, respondents were asked to evaluate the importance of 30 pre-selected attributes on a 7-point scale. Using an Internet questionnaire, 558 people responded [6]. The respondents were also asked to group the pre-selected attributes into clusters in such a way that the similar attributes according to the respondent were grouped in the same cluster. To support this task, the questionnaire was computer-aided. This also provided the possibility to use the Internet for deriving respondents and collecting data easily. Respondents were approached over the whole country in order to reach a heterogeneous response group.

The decision constructs were defined using the well-known Multidimensional Scaling approach. The input of the MDS calculations was a 30-30 data matrix with the dissimilarity data in the cells. After applying the MDS approach, five aggregated decision constructs were identified. The first construct was 'Quality of parking facilities', and included attributes about the level of information on P\&R options, the chance to find a parking place, the possibility of reserving one in advance, and the walking distance from car to the public transport service. The second decision construct was labelled as 'Quality of the P\&R facility', and was defined by safety attributes such as supervision at $P \& R$, a lighted pedestrian route and liveliness at $P \& R$, and attributes concerning additional provisions such as a heated waiting room or shopping facilities. The third construct was 'Quality of the connecting public transport' and was composed of attributes about the reliability of public transport and attributes about comfort. Finally, the constructs 'Time aspects' and 'Costs aspects' were identified. The former construct was related to attributes such as the time required to find a parking lot at the destination in the case of door-to-door car use, the amount of traffic in the city (as an indicator for congestion) and the extra travel time from the principal road to the P\&R facility. The latter construct was defined by attributes such as total costs of transferring from car to public transport, costs of road pricing and parking costs at the final destination.

Table 1 shows the cohesion between the different attributes in a cluster. This cohesion is measured as the average distance between the attributes in a (sub)cluster and tells us how, on average, travellers perceive various attributes as being rather different or closely connected. Thus, a small value in the table (the average distance) indicates a great cohesion between the attributes. The attributes within the clusters 'Quality of the P\&R facility' and 'Costs' have the strongest cohesion. In addition, the cohesion within the sub-clusters in the cluster 'Quality of the P\&R facility' is measured by calculating the distances between the centres of the sub-clusters. From these calculations it is observed that the sub-cluster 'Human contact' is situated between 'Safety' and 'Provisions'. The possibility of renting a bike instead of using public transport is situated somewhat separately. The attributes within the cluster 'Quality of the 
connecting public transport' also have a strong cohesion. Within this cluster it is found that the attributes within the sub-cluster 'Reliability' are situated more closely together than the attributes within the sub-cluster 'Comfort'. The cohesion between the attributes within the cluster 'Parking' is less strong. The attributes within the sub-cluster 'Information' are more mutually connected than the attributes within the sub-cluster 'Facilities'. Finally, the attributes within the cluster 'Time' have the smallest cohesion.

To measure the relative importance respondents attach to the attributes of a P\&R facility, they were asked to evaluate the attributes concerning the influence of the choice behaviour on a scale from 1 to 7 . The last column of table 1 not only lists the average importance scores for each individual attribute but also for each (sub)cluster. The table shows that the attribute 'Reliability' within the cluster 'Quality of the connecting public transport' is considered most important. The respondents especially consider the frequency of the public transport to be important. Furthermore, the cluster 'Time' is important to respondents. This refers to the accessibility of the city, more specifically the time required to find a parking place in the city area and the traffic density in the city. Furthermore, the costs are important, primarily the comparison between the costs of the transfer and the costs of parking at the destination. Road pricing is less relevant in this cluster. The cluster 'Quality of the parking facilities' is considered moderately relevant. The information offered to travellers appears to be more significant in this cluster than the parking facilities as such. The information of the chance of finding a parking place is very relevant. Finally, the whole cluster 'Quality of the P\&R facility' is considered less important. Within this cluster the subjective safety is relatively the most important sub-cluster (referring to the level of supervision, maintenance and liveliness). In the other sub-clusters, only a heated waiting room is slightly appreciated. The possibility to rent a bike also has a low importance.

Knowing these results, the question is what it means in terms of impacts on behavioural choices. To find some answers, a model was constructed using Stated Preference and Stated Choice techniques. Moreover, some predictive simulations using the assessed models were made focusing on the choice for either the car, or the present door-to-door public transport service, or the use of P\&R services. It goes too far to describe these analyses here and therefore we refer to [8] for the details. A few conclusions will be mentioned here. Firstly, a policy strategy focusing on improving the quality of the $P \& R$ alternative by offering a high quality of public transport will attract both car drivers and current door-to-door public transport users, although the attraction of current door-todoor public transport users is relatively limited. Since mainly car drivers are attracted, such a high-quality P\&R service seems to be able to contribute to a measurable decrease in the number of cars entering the urban area.

Secondly, the implementation of a package of policy measures in order to increase the quality of merely the parking facility at the P\&R location will have only limited effect on P\&R use. Combining the policy measures to improve the parking facilities and the urban transport services will lead to a larger increase in $P \& R$ use than the summed increase in P\&R use of the two separated packages of policy measures. 
Table 1: Clusters of attributes with influence on multi-modal choice behaviour.

\begin{tabular}{|c|c|c|c|}
\hline No & Attribute & Cohesion & Importance \\
\hline & 1 Quality of the connecting public transport (PT) & $0.26^{T}$ & $4.8^{I}$ \\
\hline & Reliability & $0.15^{2}$ & $5.0^{2}$ \\
\hline 1 & Number of transfers until destination & & 5.3 \\
\hline 2 & Frequency (number of departures per hour) of PT to the city & & 5.5 \\
\hline 3 & Separate free (bus) lane for PT to the city & & 3.8 \\
\hline 4 & Punctuality of PT from P\&R (deviating from the timetable) & & 5.3 \\
\hline 5 & Number of destinations to be reached without transferring & & 4.9 \\
\hline & Comfort & 0.45 & 4.2 \\
\hline 6 & Transport to city also possible by rail & & 3.8 \\
\hline 7 & Certainty of seat in PT to the city & & 4.5 \\
\hline & 2 Time aspects & 0.82 & 4.7 \\
\hline 8 & Time needed to look for a parking place at destination & & 4.9 \\
\hline 9 & Amount of traffic toward/in the city & & 4.8 \\
\hline 10 & Extra travel time from principal road to $\mathrm{P} \& \mathrm{R}$ & & 4.4 \\
\hline & 3 Quality of the parking facility & 0.62 & 4.0 \\
\hline & Information & 0.34 & 4.3 \\
\hline 11 & Information on the road about travel time per $\mathrm{P} \& \mathrm{R}$ and per car & & 3.7 \\
\hline 12 & Information about occupancy of the parking place of $P \& R$ & & 4.2 \\
\hline 13 & Chance to find a parking place at $P \& R$ & & 5.1 \\
\hline & Facilities & 0.89 & 3.7 \\
\hline 14 & Possibility to reserve a parking place at $\mathrm{P} \& \mathrm{R}$ & & 3.2 \\
\hline 15 & Parking lane to bring and meet travellers at $\mathrm{P} \& \mathrm{R}$ & & 3.3 \\
\hline 16 & Walking distance from parking place at $\mathrm{P} \& \mathrm{R}$ to platform PT & & 4.5 \\
\hline & 4 Costs aspects & 0.14 & 4.3 \\
\hline 17 & Total costs of transferring (parking costs + costs PT) & & 4.9 \\
\hline 18 & Costs road pricing (per car kilometre) after passing P\&R & & 3.5 \\
\hline 19 & Parking costs at destination & & 4.6 \\
\hline & 5 Quality of the $P \& R$ facility & 0.14 & 3.1 \\
\hline & Safety & 0.20 & 3.8 \\
\hline 20 & Supervision at $\mathrm{P} \& \mathrm{R}$ & & 4.1 \\
\hline 21 & Surveyed, lighted pedestrian route from parking place to $\mathrm{PT}$ & & 3.8 \\
\hline 22 & A well-maintained P\&R (clean, no graffiti, paved) & & 4.2 \\
\hline 23 & Liveliness at $\mathrm{P} \& \mathrm{R}$ & & 3.1 \\
\hline & Human contact & 0.09 & 2.8 \\
\hline 24 & Manned ticket service & & 2.8 \\
\hline 25 & Manned information desk at P\&R & & 2.8 \\
\hline & Provisions of $P \& R$ & 0.11 & 2.8 \\
\hline 26 & Heated waiting room & & 3.2 \\
\hline 27 & Kiosk & & 2.4 \\
\hline 28 & Toilet & & 3.0 \\
\hline 29 & Additional provisions (e.g. dry cleaner's, supermarket) & & 2.6 \\
\hline & Extra & $* *$ & 2.2 \\
\hline 30 & Possibility to rent a bike at $P \& R$ & & 2.2 \\
\hline
\end{tabular}

Average cohesion importance score of the cluster (in italics)

${ }^{2}$ Average cohesion importance score of the sub-cluster (in bold) (Source: [8]) 
Thirdly, a relatively large shift in mode choice is possible when offering a P\&R alternative, which is free of charge. Evidently, this might result in a rather expensive policy, although it appears to be a feasible strategy in, for example, the town of Hasselt in Belgium and a recent pilot project in the town of Leiden, the Netherlands. The combination of a free P\&R facility with policy measures to increase the quality of the P\&R alternative will lead to again higher effects in favour of P\&R use with a still low decrease in the use of the current door-todoor public transport alternative.

Fourthly, restricting parking policies such as the introduction of higher parking fees at the destination will cause a shift in favour of both the P\&R and the current door-to-door public transport alternative as the car alternative looses attractiveness. According to the assessed models the door-to-door public transport alternative will attract more users after introducing parking fees at the destination than the P\&R alternative. This effect is of course larger when the urban area is more congested. More specifically, a high-quality free of charge connecting public transport service at the P\&R facility combined with no parking fees at the $P \& R$, gives a very strong incentive to multi-modal travelling.

Summarising, our study based on extended empirical data on intended choice behaviour showed that a functional combination of policy measures aimed at improving both the quality of the P\&R facility and the connecting public transport and discouraging door-to-door car use is required to stimulate multimodal travelling. Such a policy will, according to the model, result in both an increase of P\&R use and door-to-door public transport use.

\subsection{Some conclusions}

The concept of multi-modal mobility is considered as a promising strategy in the Netherlands to tackle urban mobility problems. Basically, the largest effects will be reached when travellers leave their car at the edge of the city and travel into the city area by public transport. To reach a situation with substantive effects in this sense, various conditions have to be fulfilled. If not, travellers are not very willing to change their present choice to travel by car door-to-door to their final destination. Therefore, policy making requires good insight into the behavioural aspects of multi-modal travel behaviour.

We presented some results from a recent empirical and modelling study indicating that travellers simultaneously do take into account a variety of aspects. These aspects are related to decisions on attributes of both the transport service market (e.g. frequency, price, and comfort of public transport) and the traffic market (e.g. parking possibilities, access to P\&R). To meet this variety of requirements puts a serious challenge to the development of innovative urban mobility policies. For some of these requirements the application of advanced information and telecommunication technology (ICT) seems to offer a promising avenue. In particular we refer to requirements regarding issues as punctuality, comfort, traveller's information, service payment and parking lot reservation. We will go into depth with regard to these challenging issues in the next section. 


\section{$4 \quad$ Using ICT for improving urban transport}

\subsection{ICT as basis for intelligent transport systems}

As indicated in the introduction of this chapter, the use of new technology is considered as one of the key ingredients of innovation or urban transport management. New technology in the transport system has many faces. Think for instance about the way we built new infrastructure, the development of more environment friendly vehicle propulsion systems or the use of information- and telecommunication. In the context of this chapter, we are particularly interested in the latter type of technology, since we ended the previous section with the statement that ICT has the potential to significantly contribute to urban transport innovation. The application of ICT constitutes the heart of the development of so called Intelligent Transport Systems (ITS). In order to understand the potential contribution of ITS to the urban transport innovation, we have to structure and explain some of the underlying developments. We refer to other publications for a more extensive description and debate on these developments (e.g. [4, 5, 9, 10]).

The importance of ITS is growing rapidly. ITS refer to a large variety of innovative applications of ICT to improve the performance of transport systems. The first reason for the increasing popularity of ITS is the extremely rapid development of the field of ICT, enabling R\&D on a variety of innovative applications. The second reason is the growing awareness of the negative externalities of transport systems, such as congestion, reduced safety, pollution, land use, and noise. Increasingly, pleas are made for breakthroughs in the development of transport systems to limit these negative externalities. The idea that ITS can significantly contribute to such breakthroughs has become very popular in the last decade. Instead of building additional infrastructures, transport policy is increasingly focusing on ITS strategies to reduce avoidable transport (mobility market), to stimulate intelligent use of different travel modes (transport service market) and to optimise existing infrastructure capacity (traffic market).

Although the expectations concerning the positive impacts of ITS are high and widespread, and the variety of ITS measures is steadily growing, there still exists a considerable gap between what seems technologically possible and what has so far been achieved in practice. In the past decade an increasing amount of research is initiated for exploring issues of ITS implementation. In this context, behavioural, societal, legal, institutional and political goals, impacts and conditions are addressed.

Based on the transport systems view, described in section 2, we are able to make a functional classification of the variety of ITS technologies by linking the design functionality of these technologies with the processes that are typical for the various above-described subsystems. Table 2 shows such a classification [5]. In this table, a link is made between the subsystems, the related public policy goals (deduced from Dutch national transport policy plans), the ITS functional category and indicative ITS applications. No comprehensiveness is intended. 
In the 'mobility market', some ITS developments focus on applications to facilitate virtual mobility, aiming at a significant substitution for physical transport. Electronic services for distance working, commerce, learning or shopping, become increasingly popular. In the 'freight and passenger volume' subsystem, the focus is on ITS applications to improve pre-trip information (e.g. transport mode options, expected travel time, delays, and costs) and to collect transport service preferences. Logistic planning in the 'transport service market' uses a variety of supportive electronic tools, for example for route planning and navigation or tracking and tracing freight. ITS developments related to the subsystem 'vehicles' focus on the development of systems to improve the operational performance of vehicles, such as vehicle control or driver support with regard to, for example, distance keeping, obstacle avoidance or lane keeping. The 'traffic market' is adopting a large variety of electronic systems for dynamic traffic management.

Table 2. Indicative relationship between transportation subsystems, policy goals and ITS applications.

\begin{tabular}{|c|c|c|}
\hline Subsystem & Policy goals & Possible ITS application \\
\hline $\begin{array}{l}\text { Organisation } \\
\text { of society }\end{array}$ & $\begin{array}{l}\text { Optimise mobility of } \\
\text { people, goods, information }\end{array}$ & \\
\hline $\begin{array}{l}\text { Transport } \\
\text { need market }\end{array}$ & $\begin{array}{l}\text { Reduce unnecessary physi- } \\
\text { cal transport }\end{array}$ & $\begin{array}{l}\text { Electronic commerce; } \\
\text { tele-working; tele-education }\end{array}$ \\
\hline $\begin{array}{l}\text { Freight and } \\
\text { passengers }\end{array}$ & $\begin{array}{l}\text { Optimise access to and use } \\
\text { of transport system }\end{array}$ & $\begin{array}{l}\text { Park and ride information; } \\
\text { public transport services information; } \\
\text { traffic information on radio or } \\
\text { teletext; internet booking services }\end{array}$ \\
\hline $\begin{array}{l}\text { Transport } \\
\text { service market }\end{array}$ & $\begin{array}{l}\text { Improve logistical planning } \\
\text { (modal split, route choice, } \\
\text { time) in favour of safer, } \\
\text { cheaper and environment- } \\
\text { friendly transport }\end{array}$ & $\begin{array}{l}\text { (Multi-modal) trip reservation; route } \\
\text { planning systems; telecommunication } \\
\text { for fleet management and operational } \\
\text { control (tracking, tracing); trip } \\
\text { matching systems (e.g. carpooling) }\end{array}$ \\
\hline Vehicles & $\begin{array}{l}\text { Improve driver's comfort, } \\
\text { behaviour and vehicle } \\
\text { control }\end{array}$ & $\begin{array}{l}\text { Self-diagnostic engine control } \\
\text { systems; crash recorders; reverse } \\
\text { parking aid; navigation systems; } \\
\text { adaptive cruise/speed control; lateral/ } \\
\text { longitudinal control; co-operative } \\
\text { driving }\end{array}$ \\
\hline $\begin{array}{l}\text { Traffic flow } \\
\text { market }\end{array}$ & $\begin{array}{l}\text { Maximise use of available } \\
\text { infrastructure capacity; } \\
\text { establish a smooth and safe } \\
\text { traffic flow }\end{array}$ & $\begin{array}{l}\text { Dynamic route information; traffic } \\
\text { information on radio; electronic } \\
\text { payment; dynamic (directional) lane } \\
\text { assignment; ramp metering; speed } \\
\text { control (radar detection, cameras); } \\
\text { variable message sign; incident detec- } \\
\text { tion; aid co-ordination systems }\end{array}$ \\
\hline $\begin{array}{l}\text { Physical } \\
\text { transport } \\
\text { infrastructure }\end{array}$ & $\begin{array}{l}\text { Maximise capacity with } \\
\text { limited physical extension; } \\
\text { maintain quality }\end{array}$ & $\begin{array}{l}\text { Dynamic lane configuration } \\
\text { adaptation; surface measurement and } \\
\text { deterioration detection }\end{array}$ \\
\hline
\end{tabular}

(Source: [5], revised version) 
ITS applications in this context focus on optimising road capacity use and assuring a safe and steady flow through networks. Examples are dynamic route information screens, real-time radio traffic information or ramp metering. Finally, in the 'infrastructure' subsystem, electronic systems are implemented for road status measurement to support maintenance or dynamic traffic management.

Summarising, to explore the potentials and impacts of ITS it is important to differentiate according to the functional variety of applications and to link them to transport system goals. Diversification in scope and functional goals of ITS applications improves detailed knowledge about (potential) impacts of (new) applications. For innovation in urban transport systems, two ITS-related developments seem to be of particular interest, because they are assumed to significantly influence traveller's decision making. The first concerns the provision of information to travellers, an issue that is typically related to the functioning of the transport market. The second concerns the development of intelligent infrastructure-vehicle driver support combinations that contributes to more reliable and flexible transport services and traffic safety. This concentrates on the functioning of both the transport and traffic market.

\subsection{High quality traveller information}

With respect to the first issue, we can observe a trend in the Netherlands to improve the quality of information towards the traveller following different strategies. First, attempts are made to link information on different public transport modes into one publicly accessible (Internet and telephone) information system. People can consult this system for collecting pre-trip information on their intended trip. This information regards both normal schedules as well as planned exceptions (for example maintenance on railways or large events). Secondly, on-trip aggregated information is provided to car drivers using local dynamic traffic information facilities (inner-city parking guidance system, car radio, dynamic route information screens, et cetera) and/or in-car route guidance systems. In particular the latter system is becoming popular rapidly. Thirdly, on a minor scale tailor-made individual dynamic travel information becomes available, using mobile telephone or an on-board computer. It is expected that this service will develop towards a so-called personal intelligent travel assistant system, providing real time information on alternative ways of travelling, delays or costs and facilities for booking seats or payment. A mobile telephone might be used to order and collect such information. In sum, the trend in information supply is from static, aggregated and mono-modal information towards dynamic, multi-modal and tailor-made travel information. Clearly, this development faces a great complexity including data-collection and updating, inter-organisational co-operation and the ownership and marketing of information (e.g. [11]).

\subsection{Advanced driver assistance}

The second issue concerns the use of ICT for advanced vehicle driving. Here we enter the world of so-called Advanced Driver Assistance Systems (ADAS). 
These systems are meant to improve vehicle control or to support driver tasks concerning for instance speed control, distance keeping, navigation, roadway positioning and collision avoidance. Within the field of ITS, ADAS has the highest potential to improve road traffic performance as ADAS directly intervenes in the vehicle driving task. Some systems are already in the early market introduction phase, like adaptive cruise control and collision warning. Most of these driver support systems are, however, in the prototyping phase and have been demonstrated within experimental conditions. Most of the ADAS offer informative or warning information (for example regarding speed limit exceeding, route choices or parking). However, one can observe a tendency towards so-called assisting systems, were the systems autonomously takes decisions unless the driver overrules these decisions (such as advanced cruise control). It is generally expected that more autonomous operating systems will gain market in the next future. In recent years, for instance, fully automated car driving has been demonstrated in the US, Japan and the Netherlands.

Various basic technical questions are related to these experiments [12]. A first issue concerns whether these systems can solely be based on in-vehicle technology or do require support from communication with other vehicles and/or infrastructure systems. Automotive industries prefer to develop applications as independent as possible from infrastructure facilities, since infrastructure adaptations usually take a long time. However, more advanced applications require vehicle-infrastructure interaction. Another issue concerns the reliability of the technology: how sensible is the system performance to disturbances, for example bad signal collection due to temporary, degraded conditions (snow, fog), electromagnetic influences, insufficient data processing capacity, and the like. For instance, unexpected interference between in-vehicle electronic systems has been reported yielding complex liability issues [13]. For the time being, uncertainty about this sensitivity is an obstacle for introducing full-automated guided systems in less controlled traffic situations (such as mixed traffic including different modes and/or ADAS- and non-ADAS cars). A third issue concerns the applicability of these systems on different road networks. Should they be able to cope with the almost endless variety of road and traffic configurations or is a safe and reliable application restricted to, for instance, the motorways? Certainly for the next decade, a limited applicability of these systems at secondary roads is expected: the signalling task is quite considerable and the decision rules to be implemented are too complex to handle in the early development stage. Perhaps an exception can be made for intelligent speed adaptation and adaptive cruise control systems, which have been proven to perform satisfactorily, even for some parts of the lower level road network. Alternatively, more advanced and integrated applications in controlled situations, for example, on dedicated roads seem more plausible and feasible.

These complexities influence the expectations regarding the first adapters of ADAS technology. For example, Marchau [14] investigated these expectations in two ways. First he consulted experts using a Delphi approach. Secondly, he interviewed a variety of potential users. In the Delphi study, one of the tasks for the 50 participating international experts was to express their opinion on the type of roads and user groups for first system applications (specified as: speed 
headway keeping, front obstacle collision avoidance, lane keeping support, side obstacle collision avoidance and the autopilot).

The results are summarised in table 3. The figures in the table indicate the percentage of experts that expects this particular combination to become available first. The table indicates that freight operators are generally expected to be an important user group for each system. Safety and/or efficiency gains might be of particular importance for this market segment. For instance, as the impacts of heavy-vehicle collisions are often much more severe than those of light vehicles, the avoidance of crashes with these heavy vehicles becomes more important and economically attractive. Moreover, the ratio of ADAS equipment cost to vehicle costs is much lower for heavy vehicles than for private cars. Consequently, according to the experts, heavy-vehicle operators are likely to be the first user groups of ADAS (see also [15]). It is somewhat remarkable that bus operators are on average not considered by the experts to be very innovative with regard to ADAS.

Table 3: Expected type(s) of roads and user groups for first ADAS applications $(\mathrm{n}=50)$.

\begin{tabular}{|l|c|c|c|c|c|}
\hline System: & $\begin{array}{c}\text { Speed } \\
\text { headway } \\
\text { keeping }\end{array}$ & $\begin{array}{c}\text { Front } \\
\text { obstacle } \\
\text { collision } \\
\text { avoidance }\end{array}$ & $\begin{array}{c}\text { Lane } \\
\text { keeping } \\
\text { support }\end{array}$ & $\begin{array}{c}\text { Side } \\
\text { obstacle } \\
\text { collision } \\
\text { avoidance }\end{array}$ & Autopilot \\
\hline Road types & $28 \%$ & $24 \%$ & $34 \%$ & $26 \%$ & $85 \%$ \\
$-\quad$ dedicated roads & $84 \%$ & $68 \%$ & $82 \%$ & $64 \%$ & $34 \%$ \\
$-\quad$ rural motorways & $66 \%$ & $68 \%$ & $50 \%$ & $72 \%$ & $20 \%$ \\
$-\quad$ urban motorways & $28 \%$ & $38 \%$ & $26 \%$ & $26 \%$ & $2 \%$ \\
$-\quad$ rural roads & $8 \%$ & $28 \%$ & $2 \%$ & $26 \%$ & $0 \%$ \\
$-\quad$ urban roads & $0 \%$ & $2 \%$ & $4 \%$ & $4 \%$ & $4 \%$ \\
\hline$\quad$ no opinion & $76 \%$ & $78 \%$ & $80 \%$ & $78 \%$ & $66 \%$ \\
\hline User groups & $50 \%$ & $38 \%$ & $30 \%$ & $36 \%$ & $36 \%$ \\
$-\quad$ freight operators & $48 \%$ & $38 \%$ & $28 \%$ & $22 \%$ & $16 \%$ \\
$-\quad$ commuters & $70 \%$ & $58 \%$ & $56 \%$ & $48 \%$ & $44 \%$ \\
$-\quad$ leisure drivers & $20 \%$ & $12 \%$ & $14 \%$ & $18 \%$ & $14 \%$ \\
$-\quad$ business drivers & $14 \%$ & $18 \%$ & $10 \%$ & $14 \%$ & $14 \%$ \\
\hline$-\quad$ elderly drivers & bus operators & & & & \\
\hline
\end{tabular}

(Source: [14])

Further, Marchau [14] performed a study based on a questionnaire amongst 200 car drivers, 59 truck drivers and 165 fleet operators (37 car fleet, 32 bus fleet and 96 truck fleet). The goal was to find out what the preferences are regarding different types of ADAS and whether there exist significant differences in preference and willingness to purchase certain ADAS amongst these groups of potential users. In terms of ADAS, systems were presented for distance keeping, lane keeping and lane change. A stated preference approach and a contrast analysis were applied using attributes indicating the system's functionality, the price and the effects on travel time and fuel consumption. A first observation from the collected data was that, although potential users of ADAS do have 
hesitations, they are not negative as such about the purchase and use of ADAS. In recent years this has also been found more specifically regarding intelligent speed adaptation (ISA) (e.g. [16]). Next, although in the study of Marchau overall no big differences were found between the drivers and the fleet operators, on average the fleet operators tended to evaluate the ADAS as more comfortable and safer than vehicle drivers. Vehicle drivers have the idea that these systems might influence their freedom in driving, whereas fleet owners have a different responsibility. Car fleet operators are slightly more positive than the bus and truck fleet owners. Within the group of vehicle drivers, the truck drivers were found to be more positive about the comfort and safety effects than the car drivers. Clearly, a higher price is of more influence on the car driver's perception of attractiveness of ADAS than on the truck driver's perception. This is not surprising, given that car drivers will have to buy these systems on their own account. Bus drivers take a position between the car drivers and the truck drivers.

These findings on early technology adapters are to some degree reflected in a number of interesting experiments and applications in the Netherlands since the mid 1990s. For instance, experiments with full-automated trucks (the so-called CombiRoad concept) have been performed towards the end of the 1990s. This led to extended studies to construct an innovative underground logistics system, among others near Amsterdam Schiphol Airport, using full-automated vehicles. Further, full-automated people movers on dedicated lanes are applied on a small scale since a few years on Schiphol Airport linking the long stay parking to the main hall and in the region of Rotterdam linking a subway station to a business area [17]. Other plans have been presented in recent years for using fullautomated vehicles for freight or passenger transport by various Dutch towns. The underlying assumption is that this technology enables the elimination of expensive chauffeurs, lower fuel consumption, more safe traffic and in combination with vehicle identification and global positioning systems, more reliability in transport service.

\subsection{Some conclusions}

In this section we explored some developments regarding the developments in the field of intelligent transport systems. For the challenge to innovative urban transport, more specifically two types of technology development and applications seem of interest: the provision of high quality information to travellers and the use of advanced driver assistance systems. Recent research indicates that operators of heavy-vehicle fleets are expected to be early adapters of the ADAS technology. The freight transport sector seems to be more interested than the passenger transport sector. On the other hand, in the Netherlands the public transport sector is slightly ahead in terms of real-world applications given the people mover projects mentioned before.

Now we have discussed the second ingredient of innovation, we will discuss the third ingredient before describing the Dutch project Phileas where all three ingredients come together in an innovative mix. 


\section{Urban spatial development}

A variety of empirical studies has indicated that the structure of the spatial environment has influence on mobility patterns. Think in the context of spatial development in terms of, for instance, density of land use, the distance between residential and working or service areas, the functional mix within areas, the structure of the road network, public transport network or bicycle network, or at street level the access by car, et cetera. Sufficient empirical evidence is available that differences with respect to these characteristics do, to some degree, influence mode choice, route choice and distances travelled (e.g. [18 - 21]), although some impacts are disputed.

Building on these studies, the idea of using the opportunities offered by spatial planning to influence mobility has become one of the cores of transport policy in the Netherlands. In the Second Transport Structure Plan (1990) this was explicitly interpreted in terms of spatial choices of locations for new developments. The national policy stated that these locations should be accessible by car as well as high quality public transport, except for activities fully dependent upon road transport. Moreover, the design of the networks in combination with spatial development should include incentives to use public transport or bicycle instead of the car.

In the past decade it appeared to be difficult to implement this policy at a large scale (e.g. [22]). One of the explanations is the fact that changes in spatial patterns take time. Spatial and economic organisation of society and processes at the mobility market level, simply have another speed of dynamics than for instance logistic organisation and transport service development at the transport service market or dynamic traffic management at the traffic market. Another explanation is that on average only a small share of travellers is inclined to use public transport. Notwithstanding these difficulties of policy implementation, the idea of influencing mobility development by changing the spatial environment has remained actual (e.g. [23]). In recent years the focus of the policy has changed towards the active development of transport nodes as new urban economic centres. This is, in particular, triggered by the construction of the highspeed train line in the Netherlands from Amsterdam to the South (Brussels and Paris) and the intended line to the east (towards the Ruhr-area). The policy is that the few stations in the Netherlands where the train will stop (Utrecht, Rotterdam, Amsterdam-South and Arnhem) should be developed as concentration points for office-development creating a business environment of international level. In recent years plans for these stations have been developed, made subject of formal decision making procedures and are partly under construction.

These top-level transport node reconstruction programs have generated a counterpart in the Netherlands in terms of similar reconstruction plans for many railway stations with inter-city rail services. These plans focus on a mix or residential and business developments of a regional or national level. Examples are the towns of Den Bosch, Breda, Amersfoort, Eindhoven and The Hague, where in the past years substantial real estate projects have been realised. In fact these developments fit very well to the location policy formulated in 1990. And 
it goes further. Lower level stops for high quality public transport (e.g. regional train services or high frequency bus services on a dedicated network) are mentioned in many regional or municipal spatial development plans as the concentration areas for accommodating residential, business and retailing developments. It implies that the spatial system seems to gradually change towards a hierarchy of international, national, regional and local transport nodes that serve as the heart of a neighbourhood with new real estate projects accommodating a spatial concentration of urban activities.

These trends reflect the growing need of urban activities for being less dependent in accessibility on merely the car and a desire to improve the multimodal accessibility. And the interesting observation is that this is not only a desire of policy makers, since a substantial part of the investments in these railway station neighbourhoods is financed by private money. Where basically rail services are treated as the heart of this multi-modal accessibility, other modes might serve this need too. This thought is one of the underlying thoughts in the Phileas project in Eindhoven. In the next section, we will describe this project in more detail.

\section{A Dutch case: Phileas in Eindhoven}

\subsection{Introduction}

In this section we will describe an innovative public transport project, labelled as Phileas, in the Dutch city of Eindhoven, where the three ingredients discussed in the previous sections come together: ITS, spatial planning and multi-modal mobility.

The city of Eindhoven is a town with 206,000 inhabitants (in 2003) and lies in the southern part of the Netherlands. It is part of an urban network that includes various suburban towns with a total of about 600,000 inhabitants. Eindhoven has a long background in R\&D in technology with the foundation of Royal Philips Electronics in 1891 and the foundation of the Eindhoven University of Technology in 1956 and DAF automobile industry in the 1949 (later DAF Trucks). The city has grown steadily in terms of new road infrastructure, suburban living area development, business area development and so on. Recently the urban agglomeration has been appointed as the 'brainport' of the Netherlands in the 5th National Report on Spatial Planning. Due to the economic and population growth, the traffic problems have grown and the need for an innovative public transport concept has already been articulated in the late seventies. However, the size of the area is not large enough to for example construct a subway system.

Initially, Eindhoven planned a light rail system, but the first studies showed that the potential market was too small to make it sufficiently interesting to exploit. The cost of infrastructure development and vehicles for light rail were relatively high, compared to for example a bus system on a dedicated lane. Still, Eindhoven wanted a public transport service similar to what is normal in Light Rail systems. In the early 1990s several regional parties, amongst others vehicle 
designers, heavy vehicles industry, the university and governmental bodies decided to invest in the design of a new bus system, called Phileas, to boost the regional economy. This had three reasons.

The first is an economic reason. In the beginning of the 1990s, the Eindhoven area experienced an economic recession. Car manufacturing had already been stopped and bus industries had a hard time surviving the tough competition from abroad. Inspired by other innovations in France (Bombardier and Civis), the idea was born to develop a new regional product, an innovative bus system. A consortium of various regionally based companies (Bus manufacturing company Bova, Car manufacturer PDE (formerly known as Nedcar), Industrial automation company Simac and Bus manufacturer Berkhof) was founded under the name of APTS (Advanced Public Transport Systems).

A second motive to develop Phileas was the large amount of subsidies that Phileas could benefit from. Different ministries invested money in the project, each ministry with its own specific motives. For example, the Dutch Ministry of Housing, Spatial Planning and the Environment was interested in Phileas because of its new sustainable engine design (silent and low emission level). The Ministry of Transport, Public Works and Water Management was interested in Phileas because of the mobility issues involved.

A third important factor that stimulated the development of Phileas was the development of a large new living area (called Meerhoven) in the suburban municipality of Veldhoven, according to the Fourth National Spatial Planning Report (1990). The municipality had to make plans to connect the new housing location with the city centre of Eindhoven by means of public transport.

These each other strengthening developments resulted in the design of a semi-automated bus system using a network of dedicated lanes connecting the city centre of Eindhoven with the regional Airport $(18 \mathrm{~km})$ and the more southern situated municipality of Veldhoven $(21 \mathrm{~km})$ (see figs. 2 and 3). In the future, the network will be extended, connecting more parts of the regional area. The Phileas transport system consists of 12 buses (eleven $18 \mathrm{~m}$ buses and one $24 \mathrm{~m}$ bus) and 25 bus stops. The buses will have an average speed of about $30 \mathrm{~km} / \mathrm{h}$ and the system has been taken into operation in summer 2004. The regional government authority SRE (Samenwerkingsverband Regio Eindhoven) is owner of the Phileas system, the private public transport company Hermes is exploiting the system and Advanced Public Transport Systems Consortium (APTS) is the builder of the system. APTS is again dependent on different companies for the technology, such as Fokker SP from Hoogeveen for the bodywork, Nedcar PD\&E from Helmond for mechanic and electronic components, Traxis from Ridderkerk and NOVEM from Utrecht for motor drive, GCI from Nuenen for the energy management systems, TNO-MEP from Apeldoorn for the battery loads, University of Groningen for the man/machine interface, FROG Navigation Systems from Utrecht and Technical University of Eindhoven for electronic guidance.

In the next subsections we will discuss various aspects of the project. 

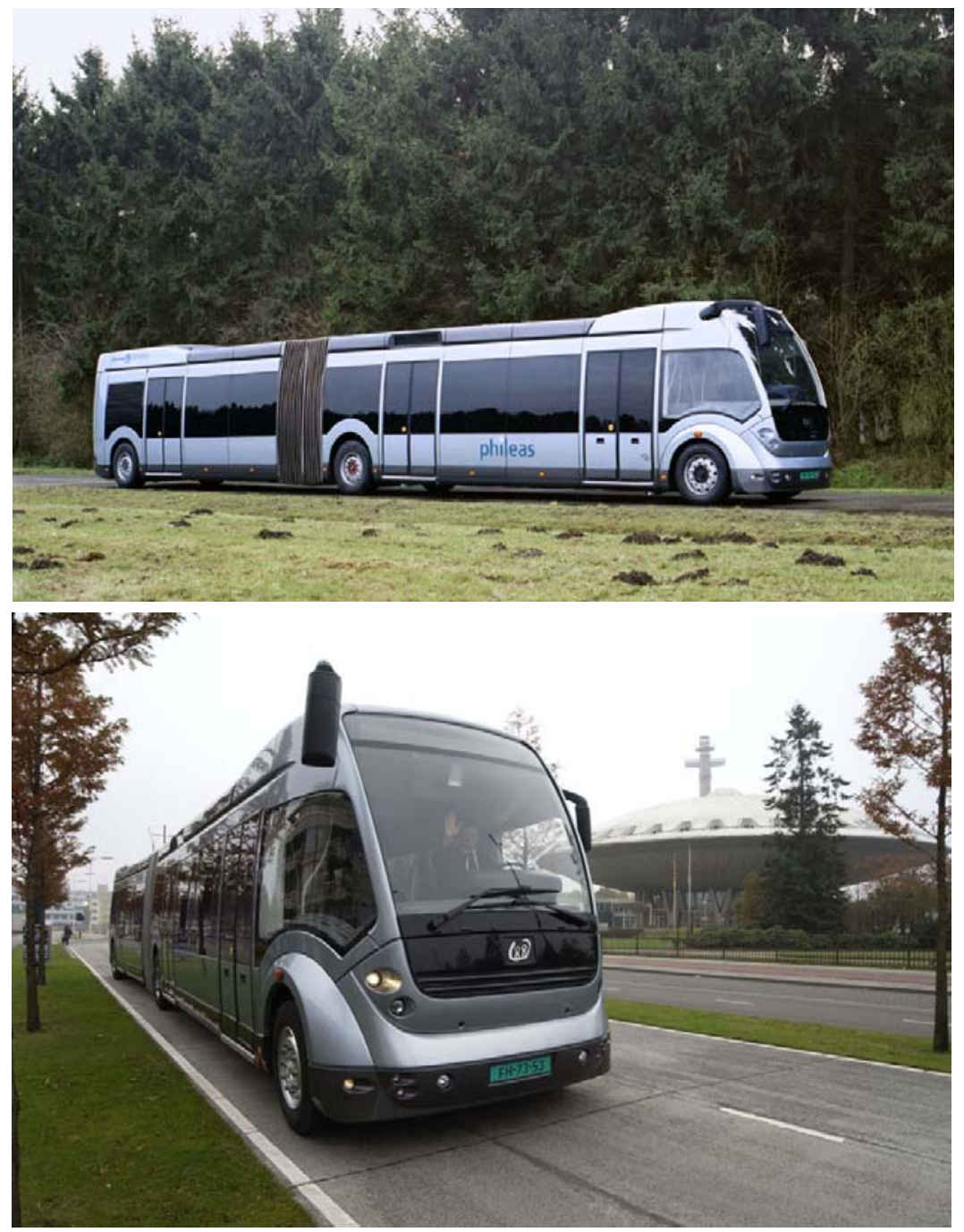

Figure 2: The Phileas bus.

\subsection{The technology applied}

The Phileas bus system is an example of Co-operative Vehicle-Highway Automation Systems (CVHAS). CHVAS are systems that provide driving control assistance or fully automated driving. These systems are based on information about the vehicle's driving environment that can be received by communication from other vehicles or from the infrastructure, as well as from their own on-board sensors [24, 25]. 


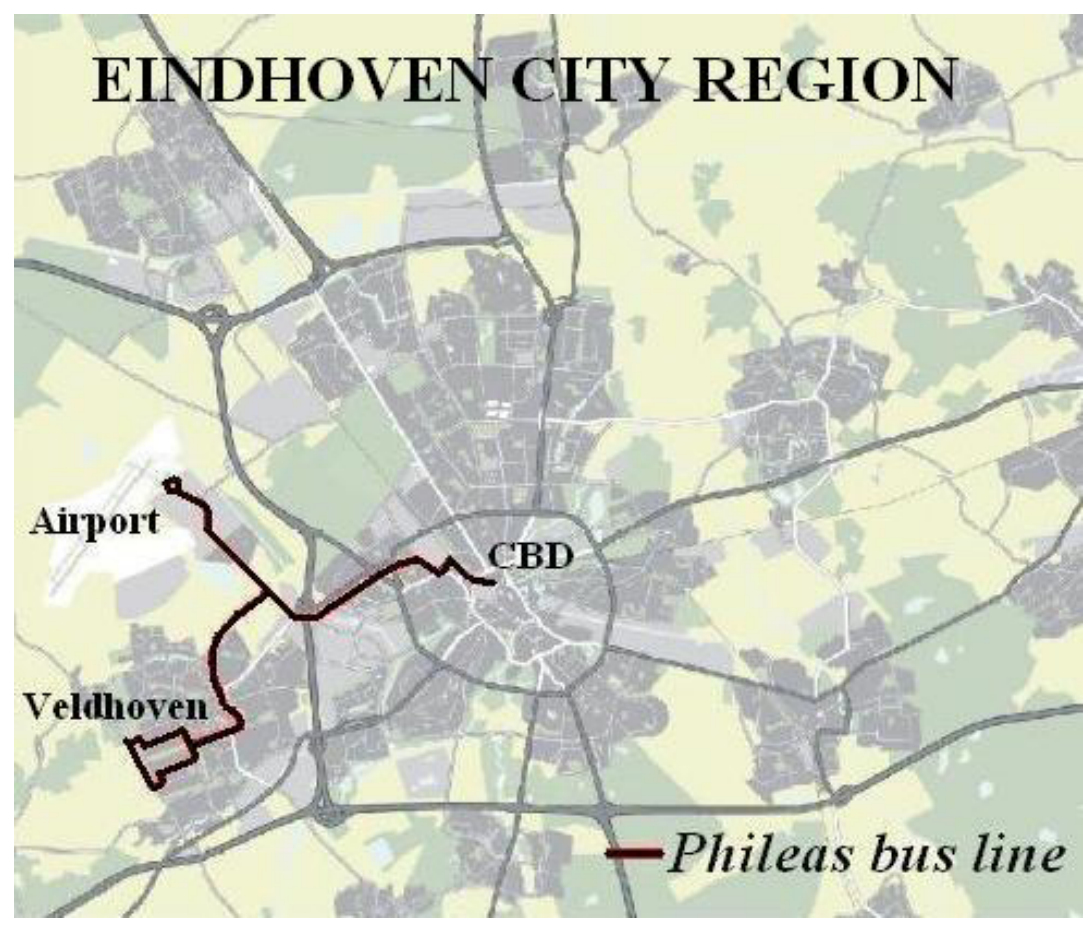

Figure 3: A map of the Eindhoven region, including the first Phileas Network.

According to Miller et al [24] it appears most likely that earliest deployments of CVHAS technologies will be on heavy vehicles operating on their own special dedicated lanes. They mention a variety of reasons:

(a) these applications are easier to develop because facilities for right of way will be granted more easily for public purposes;

(b) maturing technologies can be used more safely by professional drivers on professionally maintained vehicles than by the general public on private vehicles with different levels of maintenance;

(c) the costs of the technologies are a smaller percentage of total vehicle costs and vehicles are used much more intensively so these are amortised much faster than for passenger cars;

(d) benefits in travel time reduction, trip reliability and safety can be translated more directly into cost savings than for private cars;

(e) customised, small-lot vehicle production makes it possible to introduce CVHAS technologies into the production process faster than for automotive mass production;

(f) packaging of new technological elements is easier on larger vehicles;

(g) heavy vehicles already have more onboard electronic devices to use as a basis for more advanced support than luxury cars have.

Miller et al [24] describe a case concerning the Central Area Circulator Project (CACP) in Chicago. The purpose of the project was to develop a new transit system to interconnect all existing transit systems and link them to the 
activity centres in downtown Chicago. The interconnecting system would make it easier for travellers to use transit in Chicago thereby reducing congestion. The case of CACP is similar to the Phileas project. Miller et al show that in Chicago also the decision had to be taken between a bus system and a light rail system. They put forward some advantages of a CVHAS bus system over light rail transit that also played a role in the Phileas project in Eindhoven. One main advantage lies in the issue of speed control. CVHAS technologies enables buses to operate at the same speed as light rail services because of three reasons. The first reason is that CVHAS uses precision docking at bus stops. This can reduce dwell times, as well as provide a better quality of entry and exit service to passengers (especially mobility impaired), and reduce driver stress and maintenance problems from tire wear. The second reason is automatic steering control. This technology makes it possible to maintain full speed and good ride quality while travelling in very narrow rights-of-way, as well as permitting reduced lane width and therefore reduced capital cost. The third reason is traffic signal priority technology. Phileas uses Short Distance Radio (SDR). This technology uses wireless communications between the buses. The traffic signal system enables buses on the mainline circulator route to obtain priority over cross traffic, reducing or potentially eliminating signal delays for the passengers.

Moreover, Miller et al addressed the issue of use of available capacity. Light trains per vehicle carry more passengers than buses. However, the under-use of capacity (as compared to light rail) can be largely reduced by applying advanced technologies. Miller et al in particular refer to two technologies. The first technology is the use of electronically coupled bus platoons in a fully protected right-of-way environment that can enhance capacity and offer a high level of service to accommodate sufficiently large travel demand. The electronic coupling technology means that basically several buses can be coupled together to create a 'virtual train' and these 'virtual trains' of buses enable a more intensive use of the available infrastructure capacity than traditional light rail trains can. The initial idea was to apply this platooning technology for Phileas too. However, based on research it was concluded during the development of the Phileas that this technology is one step too far in ambition. It remains, however, an option for future development of new Phileas systems if the demand from other buyers/application areas is large enough. For the present Phileas system, capacity use has been optimised by choosing a certain size of the buses. Modern double-articulated buses of the type used in a variety of BRT systems around the world also provide significantly higher passenger capacity per bus than the traditional-unit buses. Phileas has one $24 \mathrm{~m}$ bus that is longer than normal buses (180 seats). All other buses are $18 \mathrm{~m}$ (120 seats). The buses are air-conditioned.

Phileas is driven by a hybrid (electronic and LPG) motor, has electronic steering control and a dedicated lane. The buses are constructed with the use of light-weight materials (designed by Fokker Industries). Therefore, Phileas buses only use $75 \%$ of the energy that conventional buses with similar capacity and average speed do. All wheels, except for the front two, are driven by electronic engines. The electronic energy is provided by a sustainable, environment friendly unlocked LPG-combustion engine that has a continuous-speed engine. Furthermore, the engine uses a set of batteries as a second energy source. During 
the braking of Phileas, all remaining energy is stored in the batteries. This is how Phileas is able to operate without the use of roof guidance. Compared to conventional bus systems new built Phileas prototypes reached an energy reduction of $50 \%$ under experimental conditions. Because every new bus is still, in essence, a prototype, the Advanced Public Transport Systems Consortium (APTS) aims to improve its (combinations of) technologies (e.g. engine and energy storage, steering technology performance) and aims to build different variants of Phileas buses. These variations remain, however, unnoticed by the traveller.

The electronic guidance control used by Phileas was originally developed for automated People Mover systems (such as in operation in the Netherlands at Schiphol Airport and in the town of Capelle, close to Rotterdam). The technology is further improved by FROG Navigation Systems. The FROG (Free Ranging On Grid) technology is based on a board computer on which the exact route of the vehicle is pre-programmed. Magnetic transponders sunken in the infrastructure enable correction of possible deviations from the pre-programmed route due to differences in tire pressure, road surface conditions or a minimal inaccuracy of the vehicle's map. For tracking all buses are connected to a central computer in a traffic control centre of the public transport company Hermes using Global Positioning System (GPS). The tracking information is also used to provide real-time information to passengers.

Besides the electronic guidance system, all Phileas buses are equipped with a so-called 'all-wheel drive'. This means that each pair of wheels is driven separately as well as electronically. The benefits from this are the possibility to design a precision docking system and to stop the bus from swinging like conventional buses do. The chauffeurs of Phileas therefore experience the $18 \mathrm{~m}$ bus as driving a normal car. This saves significant investments in infrastructure, since the buses need less space to manoeuvre. The automated guidance and the precision docking system of Phileas, together with large door widths, will result in shorter bus stops. The aim is to stop at stops only for 15 seconds, which is ambitious knowing that the subway system in Amsterdam only stops for 20 seconds. However, Phileas' technologies will improve a more reliable time schedule. Compared to current bus systems, where chauffeurs keep different speed averages and stop irregularly, the odds are in favour of Phileas.

\subsection{Influencing travellers' choice behaviour}

In the present situation traffic in the Eindhoven region is strongly dominated by car use. Therefore, the service level of the Phileas concept must be high enough to reach a quality level that is at least comparable to car driving in order to contribute to a mode shift. The basic goals of Phileas are to offer more comfort, reliability, better information and excellent multi-modal transfer possibilities. Moreover, Phileas has to give bus systems, in general, a better image as they are often perceived as being slow, expensive and not comfortable. Therefore, the developers of Phileas have tried to emphasise reliability, aesthetics and comfort. The result is a bus with a surprising and appealing design. 
Another important feature of Phileas that contributes to its attractiveness is a Dynamic Travel Information System (DRIS) developed by PEEK Traffic. This system, which will be implemented on all public transport stops in the city of Eindhoven, gives real-time information to travellers on time departures, arrivals and delays. The information is focussed on all public transport modes. Regarding Phileas, information will be given within buses, at bus stops and will also be available on the Internet and by the use of mobile phones. Mobile phones can use speed recognition (voice XML) and SMS services. The dynamic route information system is integrated within the traffic control centre by using standardised Trans Modal Interface (TMI). TMI translates data from the time schedule into information to control traffic lights and the DRIS.

To stimulate the use of Phileas, local and regional authorities (SRE) are implementing a strong flanking policy ('push and pull' policy). This flanking policy encompasses the following instruments:

(a) promoting other modes than car driving by setting up a mobility shop that can function as an intermediate between public transport companies and inhabitants;

(b) the set up of an active communicating line (e.g. brochures), for example to inform new inhabitants coming to live in the residential areas adjacent to the Phileas network;

(c) the promotion of the use of bicycles by building large bicycle parking areas near Phileas stops and investing in an appealing design of those parking areas. Next to this, SRE also wants to invest in the development of more bicycle lanes oriented towards Phileas stops;

(d) discourage car driving, being characterised by two main instruments: (1) decreasing the speed limit to $30 \mathrm{~km} / \mathrm{h}$ in large parts of Eindhoven, and (2) restricting the parking space, to enlarge the paid parking zone and to increase parking tariffs;

(e) linking the Phileas network to P\&R facilities at the edge of the city and stimulating the location of new economic developments in the neighbourhood of Phileas.

With respect to issue (e) we will go into more detail in the next subsection.

\subsection{Phileas and spatial developments}

As described in section 5, the third ingredient for innovation, apart from behavioural changes and the application of innovative technology, is the policy on spatial development. This third ingredient, focusing on influencing the balances on the mobility market, is therefore actively applied in the case of Phileas.

The present Phileas network is located in the so-called West-corridor of Eindhoven. This West-corridor is characterised by a mix of different activities. The integrated development of this area has been labelled as a key project in the Fourth National Spatial Planning Report in 1990. One of the aims of the Westcorridor project was to create a balance between mobility, spatial development and economic stimulation. Basically, the West-corridor distinguishes four functionally different spatial clusters: Trade Forum (leisure), Strijp S (mixed 
residential and business redevelopment area), Flight Forum (airport related economic business) and Meerhoven (new large living area). Especially the projects Flight Forum and Trade forum are initiatives from private investors.

Strijp S residential area is a former area of Royal Philips Electronics, that sold its land to the municipality of Eindhoven. Due to its inner-city location in the proximity of the central train station, Strijp S has become an attractive area for redeveloping it with a mix of new dwellings and office space. The redevelopment will take about 15 years. Phileas is an important part of the plan design.

The plan for Meerhoven consists of 3700 houses and $7500 \mathrm{~m}^{2}$ of retail facilities. The Phileas system crosses the entire planning zone (again using a dedicated road) and is supposed to significantly contribute to the fulfilment of the transport needs that are expected from future households. Apart from the pull factor Phileas, a push factor is applied. To create conditions for a more successful development of Phileas, the parking space in Meerhoven is limited to an average of one parking place for every household. This is a relatively low ratio as compared to similar developments in other Dutch cities. It is hoped that it will contribute to limiting the average car ownership in this living area.

The third important spatial development for Phileas is the implementation of the Flight Forum plan close to Eindhoven Airport (see fig. 4). The high ambition of the municipality of Eindhoven is to realise employment for 25,000 workers at this location. The aim of Flight Forum is to attract businesses that are primarily related to the regional Airport. The comprehensive plan includes 65 acres of land. $270,000 \mathrm{~m}^{2}$ are pre-served for office space and $170,000 \mathrm{~m}^{2}$ is preserved for small industrial activities. Another 30 acres is planned for public space. Although the plan to develop Flight Forum already has a long history, the integration with the innovative public transport system Phileas is something of recent date. In the present situation, the link between the renovated Flight Terminal of Eindhoven Airport and the Phileas bus stop is under construction (see fig. 4). This link is timed well. Eindhoven Airport is booming due to the increasing flights that are provided by low cost carriers as Ryan Air and Corendon. Passengers arriving at the Airport can use Phileas to reach the $P \& R$ facilities at the Trade forum (with direct access to the network of national motorways or the central train station in Eindhoven with inter-city links in all directions).

The fourth spatial cluster (Trade Forum) is situated near the A2 motorway from Amsterdam to Maastricht and the junction were the present Phileas network is split into a branch towards Eindhoven Airport and a branch towards Meerhoven in the municipality of Veldhoven. The idea of Trade Forum is to create a large leisure park of $100,000 \mathrm{~m}^{2}$ including a museum, bowling facilities, climbing wall and a large P\&R facility. Currently, the project (named NIMBUS referring to a cloud formation) is in its design stage. The private company that is planning to develop this 'Family Entertainment Centre' is TCN Property Projects. An important requirement from Eindhoven authorities regarding NIMBUS is the inclusion of a Phileas bus stop and the P\&R facility. 


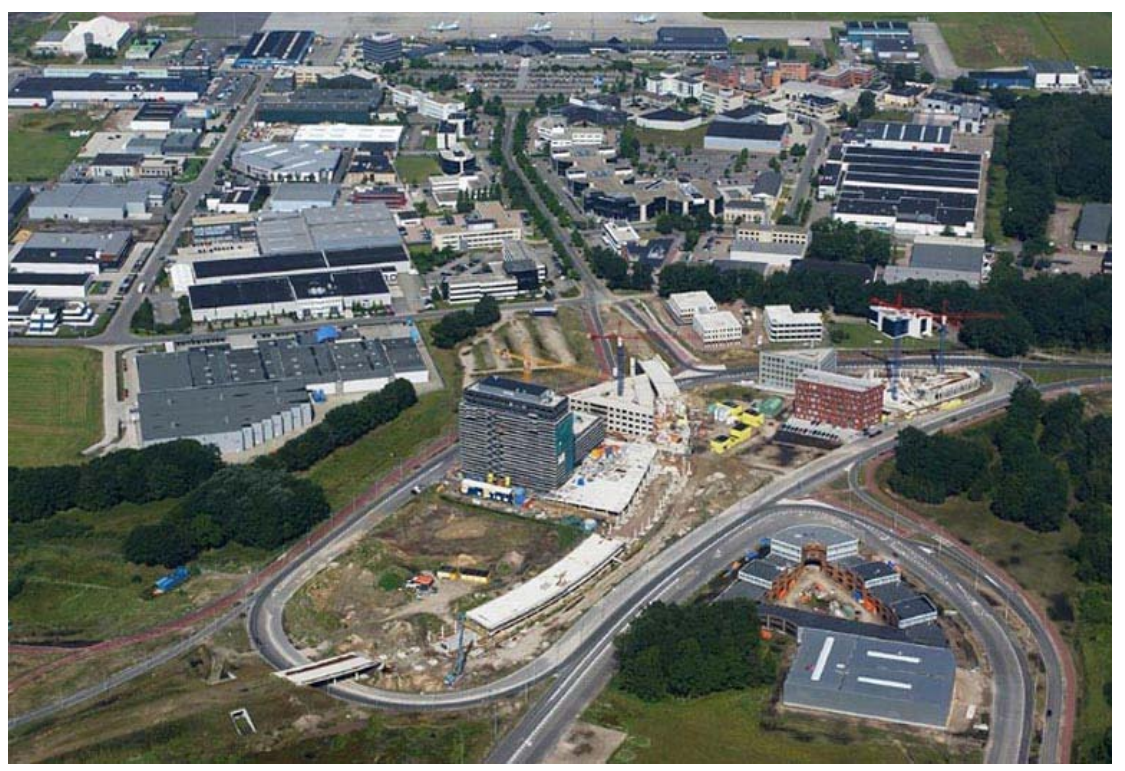

Figure 4: Phileas lane under construction at Eindhoven airport / Flight Forum.

\subsection{The future of Phileas}

Eindhoven puts much effort in Phileas to make it a success. The combination of very different developments at the right moment has resulted in an interesting and appealing concept. Whether the development will be a success depends, on the one hand, on the attractiveness for travellers. At this moment, no empirical studies are conducted on this subject. However, it is interesting to see that the presence of Phileas already seems to have influence on the attractiveness of different locations for economic development adjacent to the bus stops. Alternatively, one can evaluate the success of Phileas from the perspective of a market product. In that case Phileas can only be successful in case other cities decide to buy the buses and develop their own dedicated lanes. Of course, when Phileas becomes successful in terms of a high level of use and perhaps a measurable shift in modal split the chance that potential buyers will regard Phileas as a safe investment will increase significantly. APTS has calculated that they need to sell for about 100 buses to keep the Phileas business sufficiently profitable.

\section{Conclusions and discussion}

The innovation of urban transport management is a complex challenge. Although the nature of the problems do not differ very much among different cities, the size of the problems and the feasibility of various solutions are very much dependent upon the size of these cities. World cities can afford to 
implement severe car-restricting policies compensated by high quality public transport services (e.g. subways). Small cities have to use more subtle means of influencing car use. The effects of these more careful approaches are not known before implementation. Most of the Dutch cities struggle with this situation. They are too small to invest huge amounts of money but have too many problems to remain passive.

In this chapter we argued that the more subtle policy approaches since the early 1990s build upon at least three major ingredients with the ultimate aim to influence traveller's behaviour:

(a) the implementation of multi-modal mobility services and the creation of physical and organisational facilities to do so;

(b) the use of advanced information and telecommunication technology to significantly improve traveller's information and to improve the reliability and comfort of transport services by better vehicle control;

(c) the guidance of changes in urban activity patterns towards concentration of residential and business developments near multi-modal transport nodes.

We discussed each of these ingredients supported by some recent empirical research. To understand the relative position of these ingredients, a systems view on transport was presented first indicating that the three ingredients of policy have different anchor points: the mobility market, the transport service market and the traffic market. Although rather different in nature, the markets influence each other in terms of impacts and conditions for functioning.

With respect to the first policy ingredient it was argued that travellers make a trade-off in their travel choices among a variety of conditions and criteria. The success of the multi-modal mobility policy to a substantial degree depends upon the way these trade-offs are taken into account. The result from a model study by Bos is that a significant shift towards multi-modal travelling can be reached even in the Netherlands by a high quality system of $P \& R$ services combined with an inner-urban restrictive parking policy.

With respect to the second ingredient, we described the trends in the use of the ICT towards so-called intelligent transport systems (ITS). For innovation in urban transport management in particular, systems at the level of the transport service market and the traffic market are of interest. We referred to the improvement of traveller information and the application of advanced driver assistance systems. The quality of travel information improvements are due to the gradual introduction of systems that provide dynamic real-time information tailor-made for individual travellers. The study by Marchau indicated that the latter development is primarily adopted by heavy-vehicle fleet operators, including public transport companies. However, more integrated applications towards automated vehicle driving require a dedicated network. The advantages lie in a better fleet control by better vehicle positioning (and thus more reliability to the customer), improvement of the network throughput, more traffic safety and comfort.

Finally, with respect to the third ingredient, typical for the mobility market, it was argued that the focus of the policy strategy for systematically linking mobility management and spatial planning has shifted in the past decade to the 
concentration of business and residential developments close to multi-modal transport nodes. There seems to develop a hierarchy of network nodes varying from international to the local service level, with corresponding real estate development ambitions. Doing so, a significant effect is assumed on long-term mode-choice decision making by travellers.

These ingredients come together in the innovative Phileas bus project in the Dutch town of Eindhoven. We described how simultaneously innovations are made in terms of the driving support, the vehicle control, the information to travellers, the stimulation of multi-modal travelling by linking the Phileas stops to the bicycle network and a large P\&R at the motorway, and the anticipation of considerable spatial development plans (residential, business and leisure). The Phileas service started operating in summer 2004 and although nothing can be said yet about the ultimate success, in terms of use and changed travel behaviour, it can already be considered as a real innovation because of the successful co-ordination of problems, approaches and experts from very different disciplines and the willingness of all parties involved to take important risks. It deserves further application in mid-sized towns in the next future. 


\section{References}

[1] Banister, D., Transport Planning, SPON Press, London/New York, second edition, 2002.

[2] Ministry of Transport, Dienstverlening en Ketenmobiliteit, Dutch Ministry of Transport and Public Works, The Hague, (in Dutch), 2002.

[3] Van Nes, R., Design of multimodal transport networks; a hierarchical approach, PhD Dissertation, T 2002/5, TRAIL Thesis Series, The Netherlands, 2002.

[4] Van der Heijden, R. \& Wiethoff, M. (eds.), Automation of car driving; exploring societal impacts and conditions, TRAIL Studies in Transportation Science, 4, Delft University Press, Delft, the Netherlands, 1999.

[5] Van der Heijden, R. \& Marchau, V., Innovating road traffic management by ITS: a future perspective. International Journal of Technology, Policy and Management, 2 (1), pp. 20 - 39, 2002.

[6] Bos, I., Molin, E., Timmermans, H. \& Van der Heijden, R., Cognition and relative importance underlying consumer valuation of park-and-ride facilities. Transportation Research Record, 1835, pp. 121 - 127, 2003.

[7] Bos, I., Van der Heijden, R., Molin, E. \& Timmermans, H., The choice of Park \& Ride facilities: an analysis using context-dependent hierarchical choice experiment. Environment and Planning A, 36 (9), pp. 1673 - 1686, 2004.

[8] Bos, I., Changing seats: A behavioural analysis of $P \& R$ use, $\mathrm{PhD}$ Dissertation, T 2004/8, TRAIL Thesis Series, The Netherlands, 2004.

[9] Levine, J. \& Underwood, S., A multiattribute analysis of goals for intelligent transport system planning. Transportation Research C, 4, pp. 97 - 111, 1996.

[10] Marchau, V. \& Van der Heijden, R., Introducing advanced driver assistance systems: an exploration of market and technological uncertainties. Transport Reviews, 20, pp. 421 - 433, 2000.

[11] Van der Heijden, R., Van der Elst, A. \& Veeneman, W., Interorganisational co-operation in improving access to activity centres by public transport. Eds.: Urban Transport VIII, L. Sucharov, C. Brebbia \& F. Benitez, WIT Press, Southampton, pp. 15 - 24, 2002.

[12] Marchau, V. \& Van der Heijden, R., Innovative methodologies for exploring the future of automated vehicle guidance. Journal of forecasting, 22, pp. 257 - 276, 2003.

[13] Van der Heijden, R. \& Van Wees, K., Introducing advanced driver assistance systems: some legal issues. European Journal of Transport and Infrastructure Research, 1 (3), pp. 309 - 326, 2001.

[14] Marchau, V., Technology assessment of automated vehicle guidance, $\mathrm{PhD}$ Dissertation, Delft University Press, Delft, The Netherlands, 2002.

[15] Kanellakopoulos, I. \& Tomizuka, M., Commercial trucks and buses in automated highway systems. Automated highway systems, Ed.: P. Ioannou, Plenum Press, New York, pp. 213 - 246, 1997. 
[16] Vlassenroot, S., Intelligent speed adaptation (ISA) in Ghent, Belgium. Urban Transport X, Eds.: C. Brebbia \& L. Wadhwa, Wit Press, Southampton, pp. 433 - 442, 2004.

[17] Argiolu, R., Innovation in public transport, Master Thesis, Nijmegen School of Management, University of Nijmegen (in Dutch), 2002.

[18] Cervero, R. \& Kockelman, K., Travel demand and the 3 D's: density, diversity and design. Transportation Research D, 2 (3), pp. 199 - 219, 1997.

[19] Handy, S., Methodologies for exploring the link between urban form and travel behaviour. Transportation Research D, 1 (2), pp. 151 - 165, 1996.

[20] Van Wee, B, \& Dijst, M., Verkeer en vervoer in hoofdlijnen, Coutinho, Bussum, (in Dutch), 2002.

[21] Wegener, M. \& Fürst, F. Land-use transport interaction: state of the art, Institute of Spatial Planning, University of Dortmund, Dortmund, Germany, 1999.

[22] Martens, K., Debatteren over mobiliteit; over de rationaliteit van het ruimtelijk mobiliteitsbeleid, $\mathrm{PhD}$ Dissertation, Nijmegen University, Nijmegen, The Netherlands, (in Dutch), 2000.

[23] Meurs, H., Ruimte voor bereikbaarheid, Inaugural Lecture, Nijmegen University, Nijmegen, the Netherlands, (in Dutch), 2003.

[24] Miller, M.A., Shladover, S. \& Fishman, S., Co-operative Vehicle-Highway Automation Systems: Opportunities for Demonstrated Benefits, Proceedings of the $9^{\text {th }}$ World congress on Intelligent Transportation Systems, Chicago (CD-ROM), 2002.

[25] Misener, J.A. \& Miller, M.A., Show me the benefits: A Truck and Bus Demonstration in 2003, Proceedings of the $9^{\text {th }}$ World congress on Intelligent Transportation Systems, Chicago (CD-ROM), 2002. 